\title{
Are Gamification Projects Different? An Exploratory Study on Software Project Risks for Gamified Health Behavior Change Support Systems
}

\author{
Simon Warsinsky \\ Karlsruhe Institute of \\ Technology \\ simon.warsinsky9@kit.edu
}

\author{
Manuel Schmidt-Kraepelin \\ Karlsruhe Institute of \\ Technology \\ $\underline{\text { manuel.schmidt-kraepelin@kit.edu }}$
}

\author{
Scott Thiebes \\ Karlsruhe Institute of \\ Technology \\ scott.thiebes@kit.edu
}

\author{
Ali Sunyaev \\ Karlsruhe Institute of \\ Technology \\ sunyaev@kit.edu
}

\begin{abstract}
Gamification is increasingly utilized in information systems to afford positive experiences that are typically perceived from playing games. Despite potential benefits, gamification projects have shown to be prone for failure which may lead to severe harmful effects for its users. In traditional software projects, project managers try to mitigate failure through project risk management. However, gamification projects bring with them several differences in comparison to traditional software projects and it is unclear how extant knowledge may be transferred. We address this issue by conducting ten semi-structured interviews with experts involved in the development of gamified health behavior change support systems. Our results indicate that gamification has substantial impacts on various risk factors. We contribute to gamification and project management literature as we are among the first who conceptualize gamification projects as special software projects with different project risk factors.
\end{abstract}

\section{Introduction}

Gamification broadly refers to the proliferation of games in culture, society, and technology. Today, information systems (IS) are increasingly being gamified to afford positive experiences that are typically perceived from playing games [1, 2]. Research shows an optimistic stance toward the possible benefits of gamified IS, which include increased motivation, skill accruement [1], or engagement [3]. Likewise, practitioners increasingly seek to utilize the motivational power of gamification by implementing it in real-world IS [3, 4]. Despite potential benefits, gamification projects exhibit high failure rates and are considered to be amongst the most challenging areas of software engineering [4]. In practice, various gamification projects have failed for different reasons, such as a lack of game design knowledge [4], or the inability to add sufficient purpose to gamification elements [5]. Depending on its use context, gamification project failures can bring consequences of varying severity. Mundane consequences include financial losses or user attrition [6]. However, in some contexts, consequences may be more severe. For instance, gamification is prominently implemented in health behavior change support systems (HBCSSs) to foster beneficial health behaviors like increased physical activity [7, 8]. In such contexts, the consequences of gamification project failure may be particularly severe, as it may translate to negative influences on users' health [9].

To mitigate the risk of failure, in the context of traditional software projects, extant research has put a lot of effort into the identification and subsequent elimination of risk factors that endanger project success $[6,10]$. However, in comparison to traditional software projects, gamification projects exhibit unique characteristics, such as the need of bringing fun to system use [2], and the overall high complexity and multifaceted nature of games [11]. Consequently, from a traditional software project risk management view, it is unclear, whether and if so, how knowledge on traditional software project risks is transferable to the context of gamification projects.

Related to gamification, past research has either focused on gamifying the software engineering process [12], guidelines for designing gamified software [4, 11], or impacts of gamified software on human behavior $[3,13]$. While first studies exist that investigate potential negative outcomes of gamification [13], particularly in HBCSSs [9], gamification project risks remain largely unexplored. We, thus, currently knowledge in understanding if and how the inclusion of gamification into software projects affects the associated project risk factors that could ultimately determine project success or failure. 
Accordingly, we ask: How does the inclusion of gamification affect risk factors in software projects?

To answer our research question, we engaged in qualitative exploratory research and conducted semistructured interviews with ten experts involved in gamification projects that aimed at developing gamified HBCSSs. The contributions of our research are manifold. We are among the first to conceptualize gamification projects as software projects with project risks that may be different in nature compared to traditional software projects. In doing so, we complement extant research that has focused on the development of successful gamified IS by identifying potential negative outcomes of gamification [e.g., 9, 13], or the development of design guidelines for gamified IS [e.g., 4, 11]. For practitioners, we give an overview of the impact that gamification can have on software project risks. Such an overview can guide them in identifying, assessing, and managing risk factors while conducting gamification projects. In addition, our study may lay the foundation for the development of sophisticated countermeasures that help to mitigate the risk of gamification project failure.

This paper proceeds as follows. Section two provides the background on software project risk management and gamification projects. Our research approach is described in section three. Results of this research are presented in section four and discussed in section five. Section six concludes our paper.

\section{Background}

\subsection{Software projects risk management}

Traditionally, a software project risk has been defined as the product of uncertainty associated with risk factors and the magnitude of potential loss due to project failure $[6,10,14]$. In line with the view of Schmidt et al. [6], we define a risk factor as "a condition that can represent a serious threat to the successful completion of a software development project" [6]. The ultimate goal of project risk management is mitigating risk in order to achieve project success. According to software project management literature, before taking action, project managers first have to assess the risk, which can be further broken down into three necessary steps [6]: (1) identification of risk factors, (2) estimation of the likelihood for each risk factor to occur, along with potential damage from the risk, and (3) an evaluation of total risk exposure. To support project managers in the first step of this process, extant literature has provided them with checklists of potential risk factors. For example, Boehm [10] developed a well-cited list of ten rather abstract risk factors including personnel shortfalls and unrealistic schedules and budget. Furthermore, Barki et al. [14] provided a list of 23 risk factors derived from the literature and organized them into five categories based on survey data. Schmidt et al. [6] developed an extensive list of 53 risk factors, organized in 14 categories, by conducting an international Delphi study and by building on the lists of Barki et al. [14] and Boehm [10]. There also exist several lists for specific project contexts such as clinical IS [e.g., 15] or video games [e.g., 16]. However, we are not aware of any such list that considers the unique characteristics of gamification projects.

\subsection{Gamification projects}

Gamification refers to developments within technology, economy, culture, and society in which reality becomes more gameful [1]. Two types of gamification can be differentiated [1]: (1) intentional gamification (i.e. the intentional process of transforming a system to afford more gameful experiences), and (2) emergent gamification (i.e. a general cultural and societal transformation stemming from an increased engagement with games and gameful interactions). As gamification in HBCSSs is predominantly applied as a design strategy that explicitly aims to increase motivation or promote continuous system usage in order to ultimately sustain desirable health behaviors $[8,17]$, we solely focus on intentional gamification in this study.

Although we acknowledge that gamification can take place without software being involved (e.g., in the form of board games [18]), we also focus our research on gamified software systems. This includes the augmentation of an existing IS with game design elements as well as the development of an entirely new IS that includes game design elements. In this work, we consider a gamification project to be a special type of software project, for several reasons. First, IS have traditionally been considered to be either hedonic (i.e. pleasure-oriented systems that provide self-fulfilled values to users) or utilitarian (i.e. productivityoriented systems that provide instrumental value to users) [19]. Gamified IS, however, are systems in which both system types are being combined in convergence [2]. For instance, in HBCSSs, gamification project teams need to bring fun and pleasure to the system, while not jeopardizing the instrumental goal of the system (i.e., fostering the desired health behavior change). Balancing these two goals can prove to be a tightrope act, which requires an understanding of motivational psychology that goes beyond the requirements for traditional software 
projects [4]. Second, the effects of gamification are subject to various contextual factors, such as its application area or specific user needs $[17,20]$. These contextual factors may drastically limit the design space of gamified IS compared to games and prevent the applicability of existing knowledge [4]. We argue that these unique characteristics of gamification projects amplify their complexity in a way that can lead to fundamental differences in the presence, form, and relevance of associated risk factors.

We find two streams of research within gamification literature that are particularly related to our work. First, extant literature has started to take a look at negative outcomes of gamification, such as undermining intrinsic motivation or cheating $[9,13$, 21]. This literature stream makes important contributions to understanding and mitigating adverse effects of gamification as it focuses on identifying negative outcomes from a user perspective. However, it does not account for underlying causes of such negative effects that may lie in insufficient software project risk management. Second, a large stream of literature is concerned with the development of frameworks and guidelines for successfully designing and implementing gamification (see Morschheuser et al. [4] for an overview). However, while such literature may implicitly cover common risk factors of gamification projects, we still lack the explicit knowledge that is necessary to develop suitable risk mitigation strategies. In this work, we aim to provide such knowledge.

\section{Research approach}

\subsection{Data collection}

To answer our research question, we conducted interviews with ten experts who had overseen, led, managed, or participated in the development of gamified HBCSSs. We did not require our interviewees to fulfill any more rigorous requirements (e.g., the successful completion of a large amount of gamification projects) to be eligible for interviewing. To recruit interviewees, we contacted 72 gamification project teams from 41 different companies and 24 different research groups. Table 1 provides an overview of the interviewees' relevant demographics. Overall, we recruited five interviewees from industry and five from research groups. The gender of interviewees was equally distributed, they were 30 to 65 years of age $(M=38.9, S D=10.17)$, and reported to have working experience between one and 40 years $(M=15.4, S D=10.01)$. Furthermore, interviewees reported that they were involved in varying amounts of software projects $(M=33.6, S D=50.87)$ and gamification projects $(M=12, S D=29.38)$. Furthermore, six interviewees remarked that they had a leading position in at least one gamification project, while the remaining four did not.

We applied a semi-structured interview method for different reasons. A basic structure was necessary since we aim to contextualize existing knowledge to gamification projects. While providing such a basic structure, semi-structured interviews also leave interviewed experts with a sufficient degree of freedom to talk about aspects that might not have come to our attention during the preparation of the interview guide [22]. The interview guide was derived and discussed by two researchers. In addition, we made constant improvements to the questions in terms of clarity and comprehensibility. We applied a nonjudgmental form of listening, maintained distance, and strived to sustain an open and non-directive style of conversation during the interviews to ensure impartiality and avoid bias [22].

The interview guide was structured as follows. First, the interviewer introduced himself and explained the overall topic and objectives of the interviews. Then, the interviewer asked the interviewees about basic demographics and their experience with gamification projects. Interviewees were also asked to define important concepts, including gamification, gamification projects, risk factors, and project failure to ensure a common understanding of these concepts. Given that there are possible ambiguities in the conceptualization, as well as in the delineation of gamification from related concepts such as serious games [20], we took particular attention to ensure a common understanding of gamification. Accordingly, we presented gamification as "the use of game elements in non-game contexts" [23]. Whilst views on gamification varied slightly across individual interviewees (e.g., regarding expected outcomes), for the purpose of the interview, everyone was able to agree on the gamification definition by Deterding et al. [23]. After ensuring a uniform understanding, the interviewees were asked about which risk factors they had faced in their own gamification projects. If the interviewee was not able to think about (additional) risk factors, the interviewer fell back on a couple of trigger questions. In addition, the interviewer also used the list of top ten risk factors by Boehm [10] to make interviewees think about additional risk factors. Lastly, administrative questions were clarified. We recorded and transcribed each interview. The interviews lasted 57 minutes on average. 
Table 1: Interviewee demographics

\begin{tabular}{|c|c|c|c|c|c|c|c|c|c|}
\hline ID & Job title & Age & Gender & $\begin{array}{l}\text { \# Years of } \\
\text { working } \\
\text { experience }\end{array}$ & \begin{tabular}{|l} 
\# Soft- \\
ware \\
projects
\end{tabular} & $\begin{array}{l}\text { \# Gamif- } \\
\text { ication } \\
\text { projects }\end{array}$ & Project role & Type & Field of expertise / research area \\
\hline i01 & Project manager & 65 & male & 40 & 30 & 1 & Lead & Industry & Telecommunication \\
\hline i02 & Head of product & 32 & male & 6 & 3 & 1 & Lead & Industry & Intercultural communication \\
\hline i03 & $\mathrm{PhD}$ student & 32 & male & 4 & 1 & 1 & Lead & Research & Chronic disease self-management \\
\hline i04 & Software company director & 38 & female & 18 & 4 & 4 & Lead & Industry & Mobile health \\
\hline i05 & Chief scientific officer & 46 & male & 20 & $100^{1}$ & $100^{1}$ & Mem. & Industry & Licensing of gamified HBCSSs \\
\hline i06 & Assistant professor & 33 & female & 12 & 2 & 2 & Lead & Research & Public health \\
\hline i07 & Physician \& assistant dean & 45 & male & 23 & 10 & 1 & Mem. & Industry & Chronic disease self-management \\
\hline i08 & Assistant professor & 32 & female & 10 & $160^{2}$ & 3 & Mem. & Research & Chronic disease self-management \\
\hline i09 & Assistant professor & 36 & female & 12 & 3 & 1 & Mem. & Research & Electronic health \\
\hline i10 & Postdoctoral researcher & 30 & female & 9 & 23 & 6 & Lead/Mem. & Research & Human-Computer Interaction \\
\hline
\end{tabular}

Lead=Leading role; Mem.=Team member (in at least one gamification project)

${ }^{1}$ The interviewee's company is focused on licensing gamified IS as opposed to developing them, hence the large amount of conducted projects

${ }^{2}$ The interviewee estimated that she had done 20 software projects a year across the last 8 years, hence we estimated 160 software projects

\subsection{Data analysis}

To assess the impact of gamification on software project risk factors, we decided to base our data analysis on a combined list of risk factors proposed by Pare et al. [15] and Schmalz et al. [16]. We wanted to combine a utilitarian [15] and a hedonic [16] perspective in order to account for the unique convergence of both IS types in gamified IS. Both lists have been developed more recently than other lists [e.g., 6, 10, 14] and are thus more applicable on the modern landscape of IS development shaped by agile project teams as opposed to large and static in-house developments. The list by Pare et al. [15] has been developed for clinical IS projects which makes it particularly suitable for HBCSSs. In order to develop a combined list, we took the list by Pare et al. [15] as a basis and analyzed, which factors were also present in the list by Schmalz et al. [16] and which factors needed to be added. This process was first done by two researchers and afterwards iteratively refined through discussion with an additional researcher. The final list consists of 31 distinct risk factors which are categorized along seven dimensions (see Table 2).

For the transcribed interviews, we performed selective coding [22] using Atlas.ti 8 as our coding tool to identify text passages that deal with risk factors proposed in our combined list. An initial coding was conducted by one of the authors, subsequently discussed and iteratively refined with two additional authors. In this step, we found 166 relevant text passages in relation to 26 different risk factors. In a second step, we additionally conducted an axial coding [22] on the text passages in order to analyze the impact of gamification on the identified risk factors. Again, the coding was iteratively refined and different levels of abstractions were eliminated.

\section{Results}

Interviewees reported that gamification had an impact on several risk factors of the software projects that they were involved with. Overall, we found 34 potential impacts of gamification on 18 out of the 31 risk factors, spanning across all dimensions except the organizational dimension (see Table 2 for an overview). For the 13 remaining risk factors, our interviewees discussed 8 of them, but did not indicate any impact of gamification, and 5 risk factors were not discussed by our interviewees at all. The following sections briefly describe our findings.

\subsection{Technological risk factors}

Technological risk factors describe threats to software project success related to the complexity and performance of hard- and software components.

Introduction of a new technology. Our results indicate that gamification projects might be susceptible to the risk of introducing new technologies to the project team, as gamification might necessitate previously unused technologies. One interviewee said: "We ended up with Unity. Because of using it in our project, we had to learn the tool as well, so we ended up with things taking a lot more time than we had planned to." (i03).

Complex or unreliable technical infrastructure. In gamification projects experimentation is often necessary to tease out desired behavioral effects. Such experimentation hinges on the reliability of the technical infrastructure. One interviewee pointed out: "You need experimentation in order to figure how you should do [gamification]. So, you need to have a stable platform to experiment on before you can make these gamification changes that are effective" (i01). 
Table 2: List of relevant risk factors and the impact of gamification on them

\begin{tabular}{|c|c|c|c|c|}
\hline Dim. & Risk factor & [15] & [16] & Impact of gamification on risk factor \\
\hline \multirow{5}{*}{ 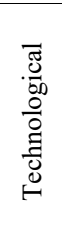 } & Introduction of a new technology & $\checkmark$ & & Gamification leads to introduction of additional new technologies, such as game engines \\
\hline & $\begin{array}{l}\text { Complex / unreliable technical } \\
\text { infrastructure or network }\end{array}$ & $\checkmark$ & & Gamification necessitates experimentation, which requires a stable technical infrastructure \\
\hline & Complex software solution & $\checkmark$ & & $\begin{array}{l}\text { Gamification exacerbates requirements for visual interfaces } \\
\text { Additional privacy features have to be realized in software because of gamification }\end{array}$ \\
\hline & Complex / incompatible hardware & $\checkmark$ & & No impact \\
\hline & Poor software performance & $\checkmark$ & & No impact \\
\hline \multirow{5}{*}{ 墨 } & Unrealistic expectations & $\checkmark$ & $\checkmark$ & People expect sophisticated gamification components, because of prior experiences with games \\
\hline & Overall resistance to change & $\checkmark$ & $\checkmark$ & No impact \\
\hline & $\begin{array}{l}\text { Lack of cooperation / } \\
\text { commitment from users }\end{array}$ & $\checkmark$ & & No impact \\
\hline & $\begin{array}{l}\text { Lack of computer skills and } \\
\text { knowledge among users }\end{array}$ & $\checkmark$ & & $\begin{array}{l}\text { Gamification employs complex interfaces akin to games, which are harder to use for people } \\
\text { inexperienced with games }\end{array}$ \\
\hline & $\begin{array}{l}\text { Prior negative experiences with } \\
\text { projects }\end{array}$ & $\checkmark$ & & 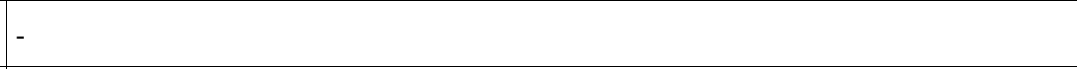 \\
\hline \multirow{4}{*}{ 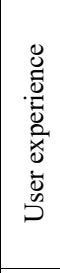 } & $\begin{array}{l}\text { Poor perceived system ease of } \\
\text { use }\end{array}$ & $\checkmark$ & & $\begin{array}{l}\text { Gamification entices developers to include overly complex game components into the system } \\
\text { Gamification necessitates privacy features, which decrease ease of use }\end{array}$ \\
\hline & Poor perceived system usefulness & $\checkmark$ & & Gamification makes hedonic value of the system overshadow the utilitarian value \\
\hline & $\begin{array}{l}\text { Misalignment of the system with } \\
\text { local practices and processes }\end{array}$ & $\checkmark$ & $\checkmark$ & $\begin{array}{l}\text { Gamification is added without deeper thought, thus does not align with local requirements } \\
\text { Gamification does not align with the context it is introduced in }\end{array}$ \\
\hline & Lack of gameful experience & & $\checkmark$ & $\begin{array}{l}\text { Gameful experience wears off, because motivational effects of gamification diminish } \\
\text { Gamification elements do not match target group's motivational preferences } \\
\text { Because of differing effects of gamification, only part of the users has a gameful experience }\end{array}$ \\
\hline \multirow{4}{*}{ 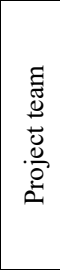 } & $\begin{array}{l}\text { Changes to membership on the } \\
\text { project team }\end{array}$ & $\checkmark$ & $\checkmark$ & No impact \\
\hline & Lack of project leadership & $\checkmark$ & & No impact \\
\hline & $\begin{array}{l}\text { Lack of required knowledge or } \\
\text { skills }\end{array}$ & $\checkmark$ & $\checkmark$ & $\begin{array}{l}\text { Gamification requires additional knowledge in behavioral economics } \\
\text { Gamification requires additional knowledge in data science } \\
\text { Gamification requires additional knowledge in persuasive design and game design } \\
\text { Gamification requires additional knowledge in graphical design }\end{array}$ \\
\hline & Lack of clear role definitions & $\checkmark$ & & No impact \\
\hline \multirow{7}{*}{.$\frac{\vec{U}}{0}$} & Large and complex project & $\checkmark$ & & Gamification requires coordination of people with vastly different perspectives \\
\hline & Scope creep & $\checkmark$ & & $\begin{array}{l}\text { Gamification only plays an auxiliary role, hence less efforts to define its scope are made } \\
\text { Unclear effects of gamification make it harder to define project scope in advance }\end{array}$ \\
\hline & Changes to requirements & $\checkmark$ & $\checkmark$ & $\begin{array}{l}\text { Rapid shifts in the state-of-the-art of gamification also translate to requirements changes } \\
\text { Gamification projects require more time, making them more prone to changes in requirements } \\
\text { Effects of gamification elements are unclear, thus require iterative testing accompanied by } \\
\text { iterative adjustment of requirements }\end{array}$ \\
\hline & Insufficient resources & $\checkmark$ & & $\begin{array}{l}\text { Effort to implement gamification is underestimated, thus an insufficient amount of resources is } \\
\text { committed to project } \\
\text { Unavailable necessary knowledge about gamification has to be substituted with other resources } \\
\text { Gamification only plays an auxiliary role, hence less resources are committed to them } \\
\text { Gamification invites the development of unnecessary resource-intensive features, }\end{array}$ \\
\hline & Lack of a project champion & $\checkmark$ & & $\begin{array}{l}\text { Gamification projects require interdisciplinary team; hence the project champion also must } \\
\text { mediate between different organizational departments with different viewpoints }\end{array}$ \\
\hline & $\begin{array}{l}\text { Lack of a formal project } \\
\text { management methodology }\end{array}$ & $\checkmark$ & $\checkmark$ & $\begin{array}{l}\text { Effects of gamification are unclear; thus, a more flexible project management methodology is } \\
\text { necessary to drive forward project } \\
\text { The nature of creating gamification experiences is creative, which can hinder the transition to a } \\
\text { professional, goal-oriented project management methodology }\end{array}$ \\
\hline & $\begin{array}{l}\text { Inadequate software development } \\
\text { strategy }\end{array}$ & & $\checkmark$ & No impact \\
\hline \multirow{3}{*}{$\dot{0}$} & $\begin{array}{l}\text { Lack of support from upper } \\
\text { management }\end{array}$ & $\checkmark$ & $\checkmark$ & - \\
\hline & Organizational instability & $\checkmark$ & & - \\
\hline & $\begin{array}{l}\text { Lack of local personnel } \\
\text { knowledgeable in IT }\end{array}$ & $\checkmark$ & & - \\
\hline \multirow{3}{*}{ 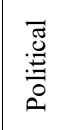 } & $\begin{array}{l}\text { Misalignment of partners' } \\
\text { objectives and stakes }\end{array}$ & $\checkmark$ & $\checkmark$ & $\begin{array}{l}\text { Gamification is an innovative technology; thus, partners may not be open to it } \\
\text { Unclear effects of gamification make it hard to convince decision-makers of gamification }\end{array}$ \\
\hline & Political games / conflicts & $\checkmark$ & $\checkmark$ & - \\
\hline & Unreliable external partners & $\checkmark$ & $\checkmark$ & Different viewpoints on gamification cause communication problems with external partners \\
\hline
\end{tabular}

- = Risk factor was not discussed by any interviewee; Dim. = Risk factor dimension 
Complex Software solution. Interviewees stated that gamification projects possibly exhibit higher requirements regarding the visual design, because fully-fledged games serve as a benchmark to determine the necessary sophistication of the user interface. As one interviewee said: "[F]or gamification [...] we want better interface design, because when we think about games a lot of times it is a lot more visual than say traditional software" (i02). Consequently, these sophisticated visuals possibly heighten the complexity of the gamified software solution. Additionally, gamification, especially social elements, often involve the processing of personal data, which can cause liabilities to include features that protect such data greatly increase system complexity.

\subsection{Human risk factors}

The human dimension contains risk factors that represent traits or attributes of the end users of an IS that may threaten project success.

Unrealistic user expectations. Our interviewees suggested that in gamification projects one should pay attention to user expectations. Users might expect a certain sophistication from gamification, caused by experience with fully-fledged games. One interviewee said: "Don't make it too difficult or too boring for people who have a lot of experience with gamification. [...] [For] young people who [...] have those super fancy games, don't make something super boring, [...] because they would then say: 'I can play all these super fun games, why should I play this?'” (i10).

Lack of computer skills and knowledge among users. User interfaces developed in gamification projects are often realized in a similar way as those in fully-fledged games, which usually feature more complex interactions as opposed to other interfaces. Thus, users lacking experience with game interfaces could contribute to gamification project failure.

\subsection{User experience risk factors}

Risk factors in the user experience dimension describe how the success of a software project can be threatened by the end users' perceptions regarding usefulness, ease of use, and motivational affordances.

Poor perceived ease of use. Developing a gamified IS can entice developers to incorporate complex gamification mechanisms into their software. Such complex gamification elements can worsen the perceived ease of use, as remarked by two interviewees: "I think you tend to try and make it very complicated when trying to gamify stuff" (i09); "[Our gamified intervention] does not include this complex leveling up and using points to level up on these skills and personal strength because it overwhelms people" (i02). Furthermore, gamification may also necessitate the addition of privacy features. Such features can be perceived as not user-friendly and, thus, threaten perceived ease of use: "Having to use a two factor authentication system to log into the app [...] would not by itself ruin the gamification, but [...] if you have to have a strict security system, which makes it hard to log in, people would not use it." (i03).

Poor perceived usefulness. The experts remarked that gamification may shift the way how a user perceives the value he or she gains from using an IS. One interviewee said: "It was an interesting thing that people game the system, so people are using the app with the intervention more just to get points as opposed in the way that the thing was intended" (i04). This indicates that the additional hedonic value created by gamification elements might overshadow the utilitarian value created by the overall IS, resulting in a loss of the original purpose of the IS, and a subsequent decrease of perceived usefulness.

Misalignment of the system with local practices and processes. Gamification projects can be prone to misalignments of the developed IS with local practices and processes, if gamification does not align with the context it is applied to. For instance, one interviewee remarked such a misalignment of gamification with a workplace setting: "They were only able to play [our game] in the office on the intranet, so they could not play it at home. But to play a game during work hours felt weird for them" (i10). Furthermore, interviewees pointed out that adding gamification without considering local requirements such as preferences of the target audience, bears the risk of causing misalignments: "I think just layering elements of gamification on existing software often feels a little bit shallow and I think there is really nothing especially magically about these techniques. It is more in your whole design. From the very beginning you have to be thinking: 'How am I going to engage my audience? How am I going to retain their attention? How am I going to compete with all the other fun things they have to do in their life, so that they are going to do my game and learn something from it? '" (i07).

Lack of gameful experience. An IS containing gamification could fail to provide a gameful experience to users, because the gamification elements do not match the users' motivational preferences, as illustrated by one interviewee: "I think the first [risk factor] is [...] not choosing the right reward to match the person's motivation" (i08). Related to this, our interviewees remarked that the effects of gamification are not the same for every user: "I think there is a huge opportunity for us to [...] deliver much more personalized gamification for it to be successful, 
because too often you are seeing [that] the [gamification] tactic was not useful for everybody, it was only useful for a small sub-group. So, I think that is a big threat because most of the gamification I have seen at least in health, is not custom to individual level behavior" (i08). Lastly, even when a gamified IS successfully provides a gameful experience, this experience could diminish over time: "Sometimes the gamification techniques could only work in a shortterm. Again, you know, it feels fresh, it feels fun but then after a little while people start stop paying attention to it. Then it is again a failure“ (i02).

\subsection{Project team risk factors}

Project team risk factors are concerned with the team members assigned to a software project, including their roles, capabilities, and guidance.

Lack of required knowledge or skills. When a gamification project reaches a certain data throughput, the project team might require additional knowledge in data science. Furthermore, a lack of knowledge in behavioral economics, persuasive design, and game design may also be critical. One interviewee asked: "[I]s it better to give people things and let them accumulate points or do you give them something and then if they don't follow a certain protocol, you begin to take that thing away? (i05). Knowledge in these fields could help to answer such questions. One interviewee also stated that knowledge in graphic design may be necessary: "[W]e eventually brought in an outside artist to help us with like color scheme and refine the way we were placing elements on the screen and that was very helpful" (i07).

\subsection{Project risk factors}

Project risk factors are concerned with the circumstances of a software project, including the project's complexity, scope, requirements, available resources, and the project management approach.

Large and complex project. In gamification projects, we found that the risk of having a large and complex project can be aggravated, because the successful creation of gamification experiences requires the coordination of an interdisciplinary team, where people have vastly different backgrounds.

Scope creep. The experts stated that gamification often is not part of the core functions of an IS, but rather only plays an auxiliary role. Consequently, project teams may not focus their efforts on properly defining the scope of gamification elements, as one interviewee described: "[G]amification [...] is not the most important part of the project. I think it takes a lot of time and a lot of trial and error, and creativity, and resources" (i03). This possibly leads to unrealistic definitions of the scope of gamification, which can subject a gamification project to scope creep. In addition, the effects of gamification are often unclear, which makes it difficult to define a realistic scope in advance: "But to specify things in detail when you make a gamification thing, that is not that easy. Because you know it is an experimental question. What is going to work?" (i01).

Changes to requirements. Experts indicated that the unclarity surrounding the effects of gamification can also form additional ground for changes in the requirements. For example, one interviewee pointed out: "There are not a lot of best practices which means you have to do more testing and then when you do more of a testing then there is more uncertainty" (i02). Furthermore, gamification projects usually take longer than normal software projects. At the same time, the state-of-the-art in gamification is rapidly shifting: "[T]he knowledge about gamification and the techniques and applications probably also changes quite quickly. So, what is new this year might [...] already be boring in two years" (i06).

Insufficient resources. Our interviewees indicated that a core issue in gamification projects is that the resources required to realize gamification may be underestimated, resulting in insufficient resources being allocated. Missing experience can be a reason for this: "Due to inexperience and the nature of our group, [...] we typically underestimate the amount of time and money it will take to build something that is a very high quality [gamification] experience" (i08). Gamification might also only be an auxiliary component of an IS and other components might be given precedence in resource allocation: "In terms of resources, and this is particularly my experience from our place, that the gamification part kind of is not the most important part of the project. [...] And the most important point is to make that application" (i03). Furthermore, the relatedness of gamification and games may entice developers to steer too far into the direction of creating a fully-fledged game as opposed to a gamification experience. This can possibly manifest in the creation of complex and resourceintensive gamification elements, draining the available resources faster than expected. For instance, one interviewee said: "So, going more for like a game feel than real gamification I think is a risk factor. And that is something we have to struggle with and always say 'Ok, let's keep it a bit more simple and see what we can do with the gamified elements instead of really going all the way and making it a very expensive and complicated game",' (i09). Furthermore, gamification projects can require additional capabilities in the 
project team. If such capabilities are unavailable, gamification project teams must substitute these missing capabilities. One expert stated: "We are not a game developer shop, so I think the amount of effort may take us to think through that logic is a larger hump to overcome than a group that maybe is just doing that as their bread and butter" (i08)

Lack of a project champion. The presence of a project champion that encourages teamwork within the project team and acts as a mediator that converges the viewpoints of different organizational departments was emphasized as particularly important by our interviewees: "So I would say [it is important to] have a researcher or have a developer [...] who bridg[es] the gap between the professional groups [...] and makes sure that your entire project group shares the same ideas and are on the same level" (i03).

Lack of a formal project management methodology. Our interviewees remarked that to tease out the effects of different gamification elements, one may require experimentation, which in turn necessitates a flexible project management approach: "If you just assume that chocolate or points give you positive reinforcement, then it might be wrong. And if you make a system that assumes certain things along those lines [...], then if you have not tried it, it may fail spectacularly, because it does not work in that situation. [...] So, you have to have flexibility all over your place" (i01). Another aspect to consider is that developing gamification is to some degree a creative process. Because of this, project managers might need to include a formal transition from a loose, creative approach, toward a professional, goal-oriented approach in order to actually create a finished product as opposed to being stuck in a creative phase: "I probably did not do a good enough job of transitioning the environment from that loose, very creative 'Hey, we have got this really cool thing we build' to 'Actually now we have a product and the product has to work and we have to refine it, because we have a bunch of users with needs and let's go,", (i07).

\subsection{Strategic and political risk factors}

The strategic and political dimension contains risk factors, which are related to an organization's strategy, as well as inter-organizational relationships.

Misalignment of partners' objectives and stakes. Our experts indicated that it can be particularly hard to gain the commitment of external partners to gamification projects when partners are not open to innovative concepts. For example, one interviewee, who had implemented gamified IS at schools, said: "If the school was enthusiastic about the use of those modern techniques, we saw more success and more enthusiasm to use it and to support it, while when we did it in a school where they were more negative about innovative things, it was more difficult" (i06). To gain the commitment of external partners to a gamification project, one has to convince them of its benefits. This, however, may be difficult, when such benefits are unclear or only visible long-term: "[For] the projects that we have worked on, [...] the return on investment is several years away. And so, I think oftentimes it is hard to make the case for gamification, [as] it is quite difficult to demonstrate its impact" (i08).

Unreliable external partners. When cooperating with external partners, our interviewees indicated that a point of contention that can lead to project failure are different viewpoints on gamification. Cooperation of partners with non-aligning viewpoints can cause communication problems, as outlined by one interviewee: "One partner was a game developer [...], the communication was very difficult. [...] In the end I think the problem was mainly that he was too creative, and I think he found it very difficult to adjust or adapt to what we academics were saying" (i06).

\section{Discussion}

\subsection{Principal findings}

In this study, we explored how the inclusion of gamification into software projects may affect the risk factors that lead to project failure. In the following, we discuss some of the most interesting findings. First, our results indicate that the inclusion of gamification into software projects can indeed produce major shifts in the nature of project risk factors. This strengthens our assumption that gamification projects can be considered as a special type of software projects with distinct risk factors. Our results also show that such impacts are broadly diversified across all dimensions and not limited to single risk factors. When comparing our findings to extant research, several analogies become apparent. For instance, our findings indicate that the perceived usefulness of a system can get altered when gamification takes on a higher value than the utilitarian purpose of an IS. Similarly, statements have been made in recent research about designing gamification, where researchers propose that designers have to control for people "gaming-thesystem" [4] and that poor gamification design can undermine intrinsic motivation [9]. Overall, this indicates that findings from research on software project risk management are to some degree transferable to gamification projects. However, such transfers should be done with care as gamification projects differ from traditional software projects. 
Second, when we analyzed the impacts of gamification on different risk factors, we noticed that several impacts can be traced back to similar underlying causes. Recurring themes across several risk factor dimensions were the unclear effects of gamification on human behavior and privacy issues. This suggests that it may be possible to alleviate several impacts of gamification on risk factors with a single or limited number of countermeasures.

Third, whereas several of the impacts of gamification on existing risk factors seemed intuitive (e.g., requiring additional knowledge in game design) other impacts were unexpected. One aspect that surprised us was that one project manager voiced his troubles in transitioning the overall project environment from a creative one to a goal-oriented one. This was interesting, as past research has conceptualized gamification as a creative process, where a high degree of formalism (e.g., in the form of strict design guidelines) is seen as potentially harmful to the creativity necessary for gamification design [4].

\subsection{Implications}

Our study yields important implications. From a research perspective, our study strengthens the theoretical assumption that the convergence of hedonic and utilitarian aspects in gamified IS leads to substantial impacts on project risk factors. It was interesting to see that many of those impacts stem from the fact that gamification project teams face a lot of uncertainties regarding the effects of gamification on human behavior. For researchers in the field of gamification this implies that rigorously developed insights into the behavioral effects of gamification may mitigate certain risk factors in the future, which strengthens calls for more research that teases out the behavioral effects of single gamification elements [2, 24]. It was also interesting to see that many experts approach gamification from a self-determination theory (SDT) perspective, which is by far the most prominent theoretical lens on gamification [25]. While we acknowledge the value of approaching gamification from an SDT perspective, we think that future research should also consider other theoretical perspectives that are more closely related to the context that gamification is applied in (e.g., theories unique to the health context for HBCSSs [26]).

For practitioners, our results provide insights into which project risk factors need to be particularly considered when it comes to designing a gamified IS. Especially project managers with extensive experience in traditional software development may benefit from our work since they are well-versed in identifying as well as countering traditional risk factors. They may complement their existing knowledge with our study results to conduct a rigorous risk management in forthcoming gamification projects.

\subsection{Limitations and future research}

The findings of this study should be interpreted in consideration of some key limitations. To avoid biasing our interviewees, we refrained from providing them with our list of risk factors during the interviews. Thus, we were not able to gather data regarding every risk factor. Adding to this, we only conducted ten interviews. Despite varying levels of expertise with gamification across interviewees, we deemed the insights of each of our experts to be valuable enough to include into our data set. However, we think that future research may find more impacts of gamification on risk factors, if more interviews are being conducted, if interviewees were more experienced and had conducted more gamification projects, or if they are shown existing lists of risk factors.

Furthermore, we conducted interviews specifically with experts from the field of HBCSSs. Despite this limitation, we feel that our results are transferable to other domains. Most of the impacts of gamification on risk factors that our interviewees remarked were related to achieving the desired hedonic effect of a gamified IS, and not related to the utilitarian purpose of the HBCSS. Given that the transfer to other domains usually primarily entails a change in utilitarian purpose of a gamified IS [4], we feel that our results to some degree transcend the context of HBCSSs. However, we also acknowledge that some of our identified impacts of gamification showed close relation to contextual factors induced by HBCSSs (e.g., increased privacy issues because of possibly sensitive health data). Hence, future research might also benefit from investigating project risk factors in contexts other than HBCSSs.

Finally, we limited us to the identification of potential impacts of gamification on project risk factors, which is related to only the first of three steps in the risk assessment process [6]. Another important step in project risk management is the development of countermeasures that help to mitigate such risk factors. It is upon future research to investigate whether and, if so, how existing countermeasures for risk factors of software projects are applicable in the context of gamification projects. Extant research has also shown that project managers may benefit from ranking risk factors regarding their damage potential and required resources for their mitigation [6]. It would be interesting to see whether the relevance of certain risk factors changes for gamification projects in comparison to traditional software development. 


\section{Conclusion}

In this study, we aimed to assess how gamification impacts risk factors that threaten software project success. To do so, we conceptualized gamification projects as a special type of software projects with distinct risk factors. By conducting ten semi-structured interviews with experts in the development of gamified HBCSS, we were able to identify 34 different impacts of gamification on 18 different risk factors. Our results grant insights into how the presence of gamification can lead to significant changes in the nature of risk factors in software projects. We contribute to both research and practice alike by fostering a deeper understanding of risk factors in gamification projects. This knowledge can be used to identify and assess risk factors, and ultimately develop sophisticated countermeasures that help to increase the success rate of forthcoming gamification projects.

\section{References}

[1] Hamari, J., "Gamification", in The Blackwell encyclopedia of sociology, G. Ritzer, Editor. 2019. John Wiley \& Sons: New York, NY, USA.

[2] Koivisto, J. and J. Hamari, "The rise of motivational information systems: A review of gamification research", International Journal of Information Management, 45, 2019, pp. 191-210.

[3] Hamari, J., J. Koivisto, and H. Sarsa, "Does Gamification Work? -- A Literature Review of Empirical Studies on Gamification", Hawaii International Conference on System Sciences, Waikoloa, HI, Jan. 06-09. 2014.

[4] Morschheuser, B., L. Hassan, K. Werder, and J. Hamari, "How to design gamification? A method for engineering gamified software", Information and Software Technology, 95, 2018, pp. 219-237.

[5] Liao, S., "Netflix decides not to gamify children's shows after all", The Verge, 03/14/2018.

[6] Schmidt, R., K. Lyytinen, M. Keil, and P. Cule, "Identifying Software Project Risks: An International Delphi Study", Journal of Management Information Systems, 17(4), 2001, pp. 5-36.

[7] Schmidt-Kraepelin, M., S. Thiebes, D. Baumsteiger, and A. Sunyaev, "State of play: A citation network analysis of healthcare gamification studies", European Conference on Information Systems, Portsmouth, UK, Jun. 23-28. 2018.

[8] Schmidt-Kraepelin, M., P.A. Toussaint, S. Thiebes, J. Hamari, and A. Sunyaev, "Archetypes of Gamification: Analysis of mHealth Apps", JMIR mHealth and uHealth, Forthcoming, 2020.

[9] Schmidt-Kraepelin, M., S. Thiebes, S. Stepanovic, T. Mettler, and A. Sunyaev, "Gamification in health behavior change support systems-A synthesis of unintended side effects", International Conference on Wirtschaftsinformatik, Feb. 23-27. 2019.

[10] Boehm, B.W., "Software risk management: principles and practices", IEEE Software, 8(1), 1991, pp. 32-41.
[11] Deterding, S., "How to Do Gameful Design", in Extended Abstracts Publication of the Annual Symposium on Computer-Human Interaction in Play, Amsterdam, NL, Oct. 15-18. 2017.

[12] García, F., O. Pedreira, M. Piattini, A. Cerdeira-Pena, and M. Penabad, "A framework for gamification in software engineering", Journal of Systems and Software, 132, 2017, pp. 21-40.

[13] Hyrynsalmi, S., J. Smed, and K. Kimppa, "The Dark Side of Gamification: How We Should Stop Worrying and Study also the Negative Impacts of Bringing Game Design Elements to Everywhere", International GamiFIN Conference, Pori, FI, May 09-10. 2017.

[14] Barki, H., S. Rivard, and J. Talbot, "Toward an Assessment of Software Development Risk", Journal of Management Information Systems, 10(2), 1993, pp. 203225.

[15] Pare, G., C. Sicotte, M. Jaana, and D. Girouard, "Prioritizing Clinical Information System Project Risk Factors: A Delphi Study", Hawaii International Conference on System Sciences, Waikoloa, HI, Jan. 07-10. 2008.

[16] Schmalz, M., A. Finn, and H. Taylor, "Risk Management in Video Game Development Projects", Hawaii International Conference on System Sciences, Waikoloa, HI, Jan. 06-09. 2014.

[17] Alahäivälä, T. and H. Oinas-Kukkonen, "Understanding persuasion contexts in health gamification: A systematic analysis of gamified health behavior change support systems literature", International Journal of Medical Informatics, 96, 2016, pp. 62-70.

[18] Taspinar, B., W. Schmidt, and H. Schuhbauer, "Gamification in Education: A Board Game Approach to Knowledge Acquisition", Procedia Computer Science, 99, 2016, pp. 101-116.

[19] van der Heijden, "User Acceptance of Hedonic Information Systems", MIS Quarterly, 28(4), 2004, p. 695.

[20] Liu D., R. Santhanam, and J. Webster, "Toward Meaningful Engagement: A Framework for Design and Research of Gamified Information Systems", MIS Quarterly, 41(4), 2017.

[21] Thiebes, S., S. Lins, and D. Basten, "Gamifying information systems-a synthesis of gamification mechanics and dynamics", European Conference on Information Systems, Tel Aviv, ISR, Jun. 09-11. 2014.

[22] Myers, M.D., Qualitative research in business and management, SAGE, Los Angeles, 2009.

[23] Deterding, S., D. Dixon, R. Khaled, and L. Nacke, "From game design elements to gamefulness", International Academic MindTrek Conference, Tampere, Finland, Sep. 28-30. 2011.

[24] Nacke, L.E. and S. Deterding, "The maturing of gamification research", Computers in Human Behavior, 71, 2017 , pp. 450-454.

[25] Seaborn, K. and D.I. Fels, "Gamification in theory and action: A survey", International Journal of HumanComputer Studies, 74, 2015, pp. 14-31.

[26] Schmidt-Kraepelin, M., S. Warsinsky, S. Thiebes, and A. Sunyaev, "The Role of Gamification in Health Behavior Change: A Review of Theory-driven Studies", Hawaii International Conference on System Sciences, Maui, HI, Jan. 07-10. 2020. 